\title{
Introduction to The Control Group and Meta-Analysis
}

\author{
Jason L. Jensen \\ University of North Dakota
}

Robert (Bob) Rodgers became my mentor and friend in graduate school. He taught me many things, about research, teaching, and life. Bob had been trained by John (Jack) Hunter and continued to work closely with him until Jack's untimely death in 2002. Their research together included methodology, as well as application of meta-analysis to organizational issues. I became involved in a couple of projects with them and when Bob retired I took on ownership of these projects and their destiny was left to me.

One of the projects was about the topic that perhaps Jack is best known for: meta-analysis. He had lamented that one of the issues in the application of meta-analytic tools, was how to deal with the fact that some studies had control groups and others did not. This is something that he and Frank Schmidt had not dealt directly with in their seminal book, Methods of Meta-analysis (1990). Certainly not accounting for differences in experimental designs in a meta-analysis can produce misleading results (see Carlson \& Schmidt, 1999). Some reviewers choose to only use control group study evidence, a practice that was unacceptable to Jack and Bob because it entailed discarding evidence. Rather, making corrections to account for study differences was preferred. This preference led Bob and Jack to publish, The Methodological War of the "Hardheads" versus the "Softheads" (Rodgers \& Hunter, 1996), and Bob and I to publish, The Intellectual Gold of Case Study Research (Jensen \& Rodgers, 2000). Their notion, which strongly impacted my own ideas about research, was that evidence about a scientific question can be garnered from many different sources using divergent designs and techniques. Since science is about the aggregation of evidence to make conclusions, primary study evidence of all types becomes data for the meta-analyst. Any proposed or supposed study difference that could impact the aggregate effect size could be tested as a potential moderator, or with mathematical corrections. The point was to derive the most accurate aggregate effect size possible, given the primary study evidence available.

Regarding the treatment of control groups in meta-analysis, there has not been a consistent technique applied. At about the time Jack and Bob were working on the project (initial paper drafts I have indicate 1991, and 1992), Viswesvaran and Schmidt (1992) published a meta-analysis comparing smoking cessation methods. They dealt with the fact that some of the studies contained control groups, by estimating a baseline level of quitting across all control groups, in order to adjust the overall 
effectiveness of interventions. In concept this is similar to the method developed in detail in this manuscript. Other researchers have certainly recognized the potential importance of control/experimental group comparisons in meta-analyses, some even specific to pretest/posttest intervention studies, and they have dealt with the issue in various ways, such as comparing effect sizes and even testing for differences (e.g., Wilson, Lipsey, \& Derzon, 2003).

The use of meta-analytic techniques has exploded in diverse academic fields. These fields sometimes diverge in their techniques because of the specific nature of the research. Thus, in certain fields there may be more attention to the determination of "quality" or, for instance, whether to incorporate non randomized designs in a meta-analysis. In fact, the discussion goes beyond control groups to distinguishing randomized designs from nonrandomized designs, and a host of other supposed quality characteristics. To my knowledge, there has not been another published technique that proposes what we do, although there has been continued attention to the challenges of incorporating control group studies with non control group studies, into a meta-analysis (FitzpatrickLewis, Ciliska, \& Thomas, 2009).

Although our academic area led us to couch the technique with regard to organizations, it is applicable to meta-analytic reviews in any area where there is inconsistent use of control groups in primary studies. As one reviewer correctly pointed out, the existence of random assignment experiments may be rare in applied settings such as organizations, but they are more common in other social and behavioral science areas. Thus, the usefulness of our technique will vary based on the topic of the metaanalysis.

\section{References}

Carlson, K. D., \& Schmidt, F. L. (1999). Impact of experimental design on effect size: Findings from the research literature on training. Journal of Applied Psychology, 84, $851-862$.

Fitzpatrick-Lewis, D., Ciliska, D., \& Thomas, H. (2009). The methods for the synthesis of studies without control groups. Hamilton, ON: National Collaborating Centre for Methods and Tools. Retrieved from http://www.nccmt.ca/pubs/non-RCT2_EN.pdf

Hunter, J. E., \& Schmidt, F. L. (1990). Methods of meta-analysis. Newbury Park: Sage Publications.

Jensen, J. L., \& Rodgers, R. (2001). Cumulating the intellectual gold of case study research. Public Administration Review, 61, 235-246.

Rodgers, R., \& Hunter, J. E. (1996). The Methodological War of the "Hardheads" versus the "Softheads". Journal of Applied Behavioral Science, 32, 189-208.

Viswesvaran, C., \& Schmidt, F. L. (1992). A Meta-Analytic Comparison of the Effectiveness of Smoking Cessation Methods. Journal of Applied Psychology, 77, 554-561.

Wilson, S. J., Lipsey, M. W. \& Derzon, J. H. (2003). The effects of school-based intervention programs on aggressive and disruptive behavior: A meta-analysis. Journal of Consulting \& Clinical Psychology, 71, 136-149. 